\title{
GLOBALIZAÇÃO E INTEGRAÇÃO FINANCEIRA E TECNOLÓGICA ENTRE OS PAÍSES EMERGENTES: O NOVO BANCO DE DESENVOLVIMENTO DO BRICS ${ }^{1}$
}

\section{GLOBALIZATION AND FINANCIAL AND TECHNOLOGICAL INTEGRATION AMONG EMERGING COUNTRIES: THE BRICS NEW DEVELOPMENT BANK}

\author{
Hindenburgo Francisco Pires \\ Universidade do Estado do Rio de Janeiro (UERJ), Rio de Janeiro, RJ, Brasil, hindenburgo@uerj.br
}

\begin{abstract}
RESUMO
Este trabalho analisa como a desregulação financeira e a falência do sistema de crédito das economias centrais (Estados Unidos da América, Reino Unido, Japão e União Europeia) estão influenciando nos processos de integração e recomposição financeira e tecnológica dos países emergentes a partir do banco de desenvolvimento do BRICS (Brasil, Rússia, Índia, China e África do Sul). O objetivo é mostrar que ações contra hegemônicas ao atual modelo financeiro neoliberal desregulado como, por exemplo: a criação do banco do BRICS, a construção de infraestrutura de gasodutos e a construção de redes paralelas à Internet que é controlada pelos Estados Unidos, poderão desencadear um rearranjo geopolítico no modelo atual de acumulação globalizado do capital financeiro internacional. Para a realização dessa investigação foram levantados e coletados dados estatísticos e informações econômicas e financeiras nas seguintes instituições de pesquisas: Banco Mundial (World Bank), Fundo Monetário Internacional (FMI), Tesouro dos EUA (U.S. Treasury), Divisão de Pesquisa e Estatística Monetárias e Negócios da Reserva Federal dos EUA Federal (Reserve Board, Divisions of Research \& Statistics and Monetary Affairs), Estatísticas da Europa (Eurostats), Organização para a Cooperação e Desenvolvimento Econômico (OCDE), Stockholm International Peace Research Institute (SIPRI) e Instituto de Pesquisa Econômica Aplicada (Ipea). A meta desse trabalho é contribuir com um conjunto de reflexões e questões para o debate sobre como a crise financeira, o endividamento dos EUA e das economias centrais estão compelindo os países emergentes a procurarem: a) novas formas de integração regional; b) arranjos econômicos, comerciais, tecnológicos e financeiros; e c) alternativas sustentáveis que minimizem as desigualdades sociais agravadas pelas políticas de mundialização do neoliberalismo econômico.
\end{abstract}

Palavras-chave Globalização; Desregulação Financeira; Desigualdade Social; Banco do BRICS.

\section{ABSTRACT}

This study analyzes the manner in which the financial deregulation and bankruptcy of the credit system of the mainstream economies (United States, United Kingdom, Japan and European Union) are influencing the financial and technological integration and restructuring processes of the emerging countries with respect to the new development bank of the BRICS nations (Brazil, Russia, India, China and South Africa). The objective is to show that actions against the current deregulated neoliberal finance model (such as the creation of the BRICS bank, construction of the pipeline infrastructure and establishment of networks parallel to the Internet, which is controlled by the United States) could trigger a geopolitical rearrangement in the current model of globalized accumulation of international finance capital. In order to conduct this investigation, we surveyed and collected statistical data and economic and financial information at the following research institutions: the World Bank, the International Monetary Fund (IMF), the U. S. Treasury, the Divisions of Research \& Statistics and Monetary Affairs of the U. S. Federal Reserve Board, Eurostat (a DirectorateGeneral of the European Commission), the Organization for Economic Cooperation and Development (OECD), the Stockholm International Peace Research Institute (SIPRI) and the Institute of Applied Economic Research (IPEA - Instituto de Pesquisa Econômica Aplicada). This study aims at providing a series of reflections and questions for the debate on how the financial crisis and the indebtedness of the United States and the mainstream economies are forcing emerging countries to seek: a) new forms of regional integration; b) economic, commercial, technological and financial arrangements; and c) sustainable alternatives that minimize social inequalities aggravated by economic neo-liberalism's globalization policies.

\footnotetext{
1 Globalization and Financial and Technological Integration among Emerging Countries: The Brics New Development Bank, comunicação apresentada na Regional Conference da International Geographical Union (IGU Moscow 2015) "Geography, Culture and Society for Our Future Earth”. Realizada na Lomonosov Moscow State University (LMSU), de 17 a 21 de Agosto de 2015. Anal disponível em: $<$ http://www.igu2015.ru/sites/default/files/public/programma_igu15_a4_elektronv_1.pdf >
} 
Keywords: Globalization; Financial Deregulation; Social Inequality; BRICS Bank

Artigo recebido para publicação em setembro de 2015

Artigo aceito para publicação em outubro de 2015

\section{INTRODUÇÃO}

\section{O Novo Banco de Desenvolvimento do Brics - uma iniciativa de multipolarização financeira global}

A primeira iniciativa de criação do Novo Banco de Desenvolvimento (NBD) e do Fundo de Reserva (FR) pelo grupo de países que reúne Brasil, Rússia, Índia, China e África do Sul (BRICS), surgiu quando da realização do Sétima Reunião de Cúpula do G20, em Los Cabos no México, em 2012, quando cinco chefes de governos desses países resolveram se reunir, fora da cúpula do G20, para discutir e analisar, a partir de consultas a seus ministros de finanças e representantes de bancos centrais, a possibilidade e a viabilidade de criação do NBD e do FR do BRICS (BATISTA JR, 2014), para juntos poderem atuar de forma coordenada na criação do NBD.

Pode-se afirmar que vários fatores praticamente compeliram o grupo de países do BRICS a constituir o NBD, o primeiro, emergiu do contexto de agravamento das crises e do fracasso das medidas de globalização e ações estimuladas pelo nexo Estado-Finanças nas economias centrais (HARVEY, 2011, p.54; PIRES, 2012, p.112-113); o segundo surgiu da dificuldade no acesso a fontes de financiamento internacional para a promoção do desenvolvimento econômico e social, principalmente no período de recessão; o terceiro resultou de divergências na adoção de políticas neoliberais, impostas pelas instituições financeiras multilaterais, que acarretaram prejuízos econômicos, agravaram as desigualdades e produziram elevados custos sociais.

Após uma análise técnica minuciosa sobre as possibilidades reais de criação do NBD, ficou acordado na Quinta Cúpula do BRICS, realizada em Durban, na África do Sul, em 27 de março de 2013, que a criação do NBD era mais que factível, tornar-se-ia uma necessidade. O documento elaborado pela 
UNCTAD, em 25 de março de 2013, "The Rise of BRICS FDI and Africa”, revelou o forte potencial que países do BRICS possuíam para atrair fluxos de capitais e investimentos externos diretos (UNCTAD, 2013).

Assim, no primeiro dia da Sexta Cúpula do BRICS, promovida em Fortaleza, entre 15 e 16 de Julho de 2014, o NBD foi constituído com aporte inicial de 50 bilhões de dólares e sede permanente em Xangai, uns dos centros financeiros mais importantes da China.

O NBD teve como objetivo central a promoção de projetos de investimento de capital, capazes de gerar o desenvolvimento social sustentável (COZENDEY, 2014) e a expansão econômica dos setores produtivos.

A Presidente do Brasil, Dilma Rousseff, em entrevista coletiva concedida em 15 de julho de 2014, após a sessão plenária da Sexta Cúpula do BRICS, forneceu detalhes sobre a composição rotativa de cinco anos dos cargos e a organização de três importantes funções administrativas no NBD: a primeira, a presidência do banco, será encabeçada inicialmente por um representante da Índia; a segunda, a presidência do conselho de administração ficará sob a responsabilidade de um representante do Brasil; a terceira, a presidência do conselho de governadores, formado por ministros dos cinco países do BRICS, ficará a cargo de um representante indicado pela Rússia. O Centro Regional Africano do banco ou o escritório regional do NBD, inicialmente, ficará na África do Sul, seguindo o princípio da rotatividade de cinco anos e, depois de transcorridos esse tempo, passará a estar localizado no Brasil.

A moeda que regerá majoritariamente os depósitos do banco continuará sendo o dólar, mas o BRICS pretende também adotar uma cesta de moedas regionais para intensificar o intercâmbio comercial e financeiro. O surgimento de uma cesta de moedas pode vir a ser o ensaio de um processo de desdolarização da economia mundial e o processo de construção de um novo meio monetário de 
equivalência geral internacional. A proposta brasileira é que todos os países tenham a mesma participação no processo de votação nas esferas de decisão dentro do NBD.

A criação do NBD, como alternativa à governança financeira do FMI e do Banco Mundial, certamente enfrentará a resistência dos EUA, que conseguiu consolidar sua hegemonia, após a II Guerra Mundial, ao produzir a mais importante moeda internacional de reserva - o dólar.

Uma importante e emblemática reação dos EUA à mobilização financeira do BRICS foi à criação do Tratado sobre o Comércio de Serviços (TISA), englobando mais de 50 governos $^{2}$, dirigido para permitir a abertura de mercados internacionais, no nicho do setor de serviços (água e alimentação, saúde, educação, comunicações, transportes, telecomunicações, comércio eletrônico, serviços financeiros, etc.), com o objetivo de conseguir a maximização irrestrita de lucros às grandes corporações multinacionais.

O processo de construção institucional do NBD e do FR do BRICS tem sido efetuado com muita cautela e embasamento técnico complexo. Em 2014, o PIB nominal dos países que constituem o BRICS somavam 16,990 trilhões de dólares, o que equivale a 22\% do PIB mundial. Nesse mesmo período, esses países contavam com 3,028 bilhões de habitantes (Tabela 1), cerca de 42,7\% da população mundial (MRE, 2015, pp.2,7), ou seja, possuíam recursos, reservas e potencial para criação do NBD.

\footnotetext{
${ }^{2}$ Segundo Sílvia Ribeiro, no artigo "Tratado entre 50 países ultrapassa tudo o que já se viu a favor das transnacionais", publicado em Agosto de 2015, pelo site Esquerda.Net:

O TISA integra um pacote de vários tratados comerciais em negociação nos quais um grupo de países, Estados Unidos à frente, procura consolidar o mercado das suas empresas e a sua esfera de poder comercial, financeiro e político. Os mais significativos são o Acordo de Parceria Transatlântica para o Comércio e o Investimento (TTIP) e o Acordo Estratégico Trans-Pacífico de Associação Económica (TPP). O primeiro é entre os Estados Unidos e a Europa (chamado informalmente de NATO económica) e o segundo é entre os Estados Unidos e vários países do Pacífico.

O mais amplo... e numericamente é o TISA, do qual participam atualmente 50 países, entre os quais Estados Unidos, Canadá, Europa, Austrália, Japão, entre outros países asiáticos, e vários latino-americanos: Colômbia, Costa Rica, México, Panamá, Peru, Paraguai e Uruguai. Juntos representam $68 \%$ do comércio de serviços a nível global.

É notória a exclusão de países dos BRICS (Brasil, Rússia, Índia, China e África do Sul), embora a China tenha pedido, sem sucesso, para se incorporar no TISA. É clara a intenção de afirmar a concorrência económica com esse bloco e outros do Pacífico liderados pela China.
} 


\begin{tabular}{ll}
\hline Países-membros & Brasil, Índia, China, Rússia e África do Sul \\
\hline PIB nominal & US $\$ 16,990$ trilhões (22\% do PIB mundial) \\
População & 3,028 bilhões de habitantes (42,7\% da população mundial) \\
Exportações totais & US $\$ 3,468$ trilhões \\
Importações totais & US $\$ 3,033$ trilhões \\
Saldo comercial & US $\$ 435$ bilhões \\
\hline
\end{tabular}

Tabela 1. Fonte: MRE/DPR/DIC, 2015.

Mas, para que essa iniciativa tivesse credibilidade e eficácia, esses países procuraram estabelecer acordos e tratados consensualizados com relação às características técnicas do NBD e do FR do BRICS.

O NBD resulta do profundo estreitamento dos laços de cooperação entre esses países, com o objetivo de corrigir as limitações das instituições multilaterais na gestão política da crise financeira internacional do capitalismo, ou seja, o NBD representa uma iniciativa que busca gerar alternativas de cooperação multilateral, com vista à superação da crise financeira e à definição de novos rumos à crise da economia global.

Assim, a constituição do NBD tenderá a reduzir a assimetria existente do poder econômico das economias centrais do norte sobre as economias emergentes do sul, nas esferas de decisão das instituições financeiras multilaterais globais.

\section{FUNDO DE RESERVAS DO BRICS}

A construção do Fundo de Reservas (FR) do BRICS tem o propósito de criar uma rede de proteção mutua e um acordo para o estabelecimento de um Arranjo Contingente de Reservas (Contingency Reserve Arrangement), que possibilitará o combate do risco da volatilidade das finanças internacionais (ROUSSEFF, 2014). 
Essa rede de proteção foi estimada em 100 bilhões dólares, dos quais 41 bilhões serão aportados pela China, 18 bilhões pelo Brasil, Rússia e Índia e 5 bilhões pela África do Sul (NETTO, 2014; LIMA, 2014). Assim, como se pode constatar, a partir do montante de dinheiro aportado para manter o FR do BRICS, a China, com $61 \%$ do PIB nominal e $45 \%$ da população do BRICS (Tabela 2), desempenhará um papel central na manutenção das reservas da rede de proteção do BRICS.

\begin{tabular}{lccccc}
\hline BRICS & Brasil & Rússia & Índia & China & África do Sul \\
\hline População & $7 \%$ & $5 \%$ & $41 \%$ & $45 \%$ & $2 \%$ \\
PIB & $14 \%$ & $11 \%$ & $12 \%$ & $61 \%$ & $2 \%$ \\
Exportação & $6 \%$ & $14 \%$ & $9 \%$ & $68 \%$ & $3 \%$ \\
Importação & $8 \%$ & $9 \%$ & $15 \%$ & $65 \%$ & $3 \%$ \\
\hline
\end{tabular}

Tabela 2. Fonte: MRE/DPR/DIC, 2015.

O FR do BRICS é um acordo intergovernamental, não é uma instituição como o NBD, pois as reservas permanecem sob administração e controle dos bancos centrais dos países signatários e estas só poderão ser desembolsadas em contextos de extrema necessidade, de acordo com procedimentos a serem estabelecidos, como nos casos de agravamento de uma crise financeira que possa por em risco a estabilidade econômica de um dos países membros, principalmente quando esses países passam por problemas de endividamento e agravamento no balanço comercial.

A criação de um FR do BRICS sinaliza também a necessidade de criar mecanismos próprios de regulação financeira e gerar um ambiente mais equilibrado para a governança financeira, contrários à crise e ao clima de instabilidade que tem afetado as diferentes esferas da economia internacional.

O FR do BRICS representa uma iniciativa complementar, cuja uma de suas metas é a construção de uma rede de segurança financeira adicional aos arranjos financeiros multilaterais, importantes em períodos de crise e de instabilidade financeira. Essa iniciativa reforça a necessidade de mudar o controle que vem sendo desenvolvido pelas duas instituições multilaterais sob ou a égide dos EUA, o único país com poder de veto sobre as decisões efetuadas pelo FMI. 
A criação do FR do BRICS é uma iniciativa de caráter político, que tem um significado técnico, econômico e financeiro, não é uma iniciativa de ruptura e também não é nenhuma substituição dos mecanismos de regulação financeira existentes, até porque os BRICS são membros do FMI, do Banco Mundial e do G20. Segundo Paulo Nogueira Batista Jr., representante do Brasil no Fundo Monetário Internacional (FMI), não haveria impedimentos, no futuro, para que o FR do BRICS venha à cooperar com FMI ou com Banco Mundial.

\section{A AUSÊNCIA DE REFORMAS NO FMI E NO BANCO MUNDIAL COMO FATOR À CRIAÇÃO DO NBD DO BRICS}

A criação do NBD do BRICS teve o propósito de superar o atraso existente na gestão administrativa das duas principais instituições financeiras - o Fundo Monetário Internacional (FMI) e o Banco Mundial, constituídas em 1944, na conferência mundial de Bretton Woods, realizada no Estado americano de New Hampshire, para estabelecer as novas bases e a segurança do sistema econômico e monetário internacional, do pós-guerra.

Ainda hoje em pleno século XXI, a presidência do Banco Mundial é reservada apenas a cidadãos estadunidenses e a direção do FMI, a cidadãos europeus. No FMI, a União Europeia possui um terço dos votos e quase vinte por cento da economia mundial, ou seja, não houve um ajuste nessas entidades que ajudasse a promover uma mudança no quadro geopolítico, principalmente na definição da importância que economias nacionais deveriam merecer.

No Banco Mundial, o Brasil possui apenas um entre os vinte quatro representantes, oito são europeus (1/3 da diretoria); isso, mesmo o Brasil estando, desde 2010, entre os dez maiores cotistas do fundo (BATISTA JR, 2014). A possibilidade do Brasil vir a ter uma representação compatível com sua condição de cotista depende ainda de uma ratificação a ser efetuada pelo Congresso dos EUA. 
No Banco Mundial, as decisões são sancionadas "sob o princípio de votação consoante a percentagem de capital e não de 'um país um voto' (o princípio que governa a ONU)" (PATNAIK, 2014), por esse critério, os países que possuem maiores cotas passam a impor políticas econômicas neoliberais, estabelecidas a partir de programa estruturais de ajustes (SINGER, 2000, p.101) ou de "austeridades", para concessão de assistências ou ajudas financeiras emergenciais (MENDOZA, 2015, p.15-16).

A desregulamentação e a liberalização dos mercados formam parte do conjunto de medidas neoliberais globalizantes perpetradas pelas instituições financeiras internacionais aos Estados Nacionais endividados, que solicitam empréstimos e recursos financeiros para superar momentos de crise. Essas medidas, executadas através de programas de ajuste econômicos, vêm sendo consagradas, como princípios da "boa governança", pela mídia e pela pretensa competência científica dos think tanks desses organismos internacionais (ALTVATER, 2010, p.101).

A advogada Christine Lagarde tornou-se o quinto representante francês a ocupar a Direção Geral do FMI e, desde 1946, ela passou a ser o décimo primeiro representante europeu, indicado para dirigir o FMI, ou seja, o FMI funciona quase da mesma forma desde a sua fundação há 71 anos (1944).

\section{CONSIDERAÇÕES FINAIS}

A falta de mudança nos organismos internacionais, originados da conferência de Bretton Woods, e 0 fraco poder de representação da maioria dos países signatários foram fatores causais para 0 surgimento do NBD.

A manutenção dessas antigas "salvaguardas jurídicas", que mantêm direitos unilaterais, aos quais os EUA e a Europa ainda se apegam, não é mais reconhecida pelos países emergentes, por isso, a legitimidade das instituições de Bretton Woods está perdendo a credibilidade (EL-ERIAN, 2014). 
O princípio da multilateralidade vem sendo substituído e minado pelo discurso do "multistakeholdismo", esse discurso é cada vez mais dominante nos fóruns e nas reuniões coordenadas pela ONU, como por exemplo, a Conferência Mundial de Telecomunicações Internacionais, o Fórum da Governança da Internet e a Cúpula Mundial sobre Sociedade da Informação (PIRES, 2014).

Portanto, mesmo com a participação ativa de muitos representantes do BRICS no FMI, falta ainda muito para que essa instituição efetue uma reforma administrativa e consolide uma efetiva redistribuição do poder e se torne uma instituição verdadeiramente multilateral.

\section{REFERÊNCIAS}

ALTVATER, Elmar. O fim do capitalismo como o conhecemos. Rio de Janeiro, RJ: Editora Civilização Brasileira, 2010.

BATISTA JR, Paulo Nogueira. O Banco do Brics. Brasília: TV Senado - Agenda Econômica: Entrevista com o Diretor Executivo do FMI, 14 julho de 2014. Disponível em: <https://www.youtube.com/watch?v=T9sg4cRejGU> [Acessado em agosto de 2015]

COZENDEY, Carlos. Banco do Brics. Brasília: TV Brasil Internacional: Conexão Internacional: Entrevista com o Secretário de Assuntos Internacionais do Ministério da Fazenda, 11 junho de 2014. Disponível em: $<$ https://www.youtube.com/watch?v=aDPwn7sgihc > [Acessado em agosto de 2015]

EL-ERIAN, Mohamed A. A fragmentação de Bretton Woods. São Paulo, SP: Valor Econômico, 20 de agosto de 2014. Disponível em: <http://www.valor.com.br/opiniao/3660472/fragmentacao-de-bretton-woods> [Acessado em agosto de 2015]

HARVEY, David. O Enigma do Capital e a Crise do Capitalismo. São Paulo, SP: Boitempo, 2011.

LIMA, Samatha. Banco dos Brics é resposta a falta de mudança no FMI, diz embaixador. São Paulo, SP, Folha de São Paulo do Rio, 8 de julho de 2014. Disponível em: <http://www1.folha.uol.com.br/mundo/2014/07/1482900-banco-dos-brics-eresposta-a-falta-de-mudanca-no-fmi-diz-embaixador.shtml $>$ [Acessado em agosto de 2015]

MENDOZA, Kerry-Anne. Austerity: The demolition of the Welfare State and the Rise of the Zombie Economy. Oxford, UK: New Internationalist Publications Ltd, 2015.

MRE - Ministério das Relações Exteriores. BRICS: Comércio Exterior. Brasília, DF: Departamento de Promoção Comercial e Investimentos - DPR e Divisão de Inteligência Comercial - DIC, junho de 2015. Disponível em:

<http://www.investexportbrasil.gov.br/sites/default/files/publicacoes/indicadoresEconomicos/ComExtBRICs.pdf> [Acessado em agosto de 2015]

NETTO, Delfim. O banco dos BRICS. São Paulo, SP: Carta Capital: Economia - Análise, 15 de julho de 2014. Disponível em: <http://www.cartacapital.com.br/revista/808/o-banco-dos-brics-2173.html> [Acessado em agosto de 2015]

PATNAIK, Prabhat. O banco dos BRICS. Brasília: Pátria Latina, 28 de julho de 2014. Disponível em: $<$ http://www.patrialatina.com.br/editorias.php?cod=14082> [Acessado em agosto de 2015] 
PIRES, Hindenburgo Francisco. O Controle da Governança da Internet: A rearticulação do discurso nas redes sociais. Scripta Nova - Revista Electrónica de Geografia y Ciencias Sociales, Universidad de Barcelona. Vol. XVIII, núm. 493 (53), 1 de noviembre de 2014. Disponível em: <http://www.ub.edu/geocrit//sn/sn-493/493-53.pdf > [Acessado em agosto de 2015]

O Capitalismo Gestor de Dinheiro e Desregulação Financeira: O endividamento dos EUA e da economias centrais. In: Globalização, políticas públicas e reestruturação territorial / Susana Mara Miranda Pacheco e Mônica Sampaio Machado, Orgs. - Rio de Janeiro, RJ: 7 Letras, 2012.

RIBEIR0, Silvia. Tratado entre 50 países ultrapassa tudo o que já se viu a favor das transnacionais. Lisboa: Esquerda.net, 22 de Agosto de 2015. Disponível em:

<http://www.esquerda.net/artigo/tratado-entre-50-paises-ultrapassa-tudo-o-que-ja-se-viu-favor-dastransnacionais/38234> [Acessado em agosto de 2015]

ROUSSEFF, Dilma. Entrevista coletiva concedida após a sessão plenária da Sexta Cúpula do BRICS. Fortaleza, CE: TV$N B R, 15$ de julho de 2015. Disponível em: <https://www.youtube.com/watch?v=dwBMopZZZn0> [Acessado em agosto de 2015]

SINGER, Paul. Para entender o mundo financeiro. São Paulo, SP: Editora Contexto, 2000.

UNCTAD - United Nations Conference on Trade and Development. The Rise of BRICS FDI and Africa. New York, EUA: United Nations, 25 March 2013. Disponível em: <http://unctad.org/en/PublicationsLibrary/webdiaeia2013d6_en.pdf> [Acessado em agosto de 2015] 